\title{
Design of a MRAS, Speed and Flux Estimators used in Sensorless Control of Induction Motors
}

\author{
N. Ben Si Ali and N. Benalia
}

\begin{abstract}
Model reference adaptive system (MRAS) based techniques are one of the best methods to estimate the rotor speed. Speed and torque control of an induction motor is usually attained by application of a speed or position sensor. However, these require the additional mounting space, reduce the reliability and increase the cost of the motor. The recent trend in field oriented control (FOC) is towards the use of sensorless techniques that avert the use of speed sensor and flux sensor. This paper seeks to provide a direct comparison between two technics of induction motor MRAS based speed estimators, one based on the rotor flux and the other based on the back EMF. Comparison between the two techniques is made through computer simulations.
\end{abstract}

Keywords-Induction motor drive, adaptive observer, MRAS, stability analysis.

\section{INTRODUCTION}

$\mathrm{M}$ ODEL Reference Adaptive System (MRAS) represents one of the most attractive and popular solutions for sensorless control of induction motor drives. Many electronic drivers for the induction motor control are based on sensorless technologies. Adaptive observers introduced by [1,2] were a powerful prolongation of initial sensor based observers.

The MRAS approach has the immediate advantage in that the model is basic and very easy to practice. The most common MRAS structure is that based on the rotor flux error vector [3] that provides the advantage of producing rotor flux angle forecast for the field orientation plan. Other MRAS structures have also been proposed recently that use the back EMF and the reactive power as the error vectors estimators $[4,5]$.

In this paper two methods of MRAS based speed estimators are proposed. One based on rotor flux estimation and the second based on back EMF estimation.

N. Ben Si Ali, Department of Electrical Engineering, Badji Mokhtar university, Annaba, Algeria, (e-mail: bensialin@yahoo.fr)

N. Benalia, Department of Electrical Engineering, Badji Mokhtar university, Annaba, Algeria, (e-mail benalianadia13@yahoo.com)

\section{MACHINE MODELLING}

Basic equations of induction motor in a general reference frame in terms of complex space vector quantities are [6]:

$$
\begin{aligned}
& \underline{u}_{s}=R_{s} \underline{-}_{s}+\frac{d}{d t} \underline{\psi}_{s}+j \omega_{s} \underline{\psi}_{s} \\
& 0=R_{r} i_{r}+\frac{d}{d t} \underline{\psi}_{r}+j\left(\omega_{s}-\omega\right) \underline{\psi}_{r}
\end{aligned}
$$

Where:

$\underline{u}_{s}=u_{s d}+j u_{s q}:$ Stator voltage vector

$\underline{i}_{s}=i_{s d}+j i_{s q}:$ Stator current vector

$\underline{i}_{r}=i_{r d}+j i_{r q}:$ Rotor current vector

$\psi_{r}=\psi_{r d}+j \psi_{r q}:$ Rotor flux vector

$\underline{\psi_{s}}=\psi_{s d}+j \psi_{s q}:$ Stator flux vector

$L_{s}, L_{r}, L_{m}$ : Stator, rotor and mutual inductance respectively.

$R_{s}, R_{r}:$ Stator and rotor resistance

$\sigma=1-\frac{L_{m}^{2}}{L_{s} L_{r}}:$ Leakage coefficient

$\omega_{s}, \omega$ are the stator angular frequency, the motor angular velocity respectively.

The stator and rotor flux linkages are:

$$
\begin{aligned}
& \underline{\psi_{s}}=L_{s} \underline{i}_{s}+L_{m} \underline{i}_{r} \\
& \underline{\psi}_{r}=L_{r} \underline{i}_{r}+L_{m} \underline{i}_{s}
\end{aligned}
$$

Under the rotor flux orientation conditions (FOC) the rotor flux is aligned on the d-axis. The electromagnetic torque equation is:

$$
T_{e m}=\frac{3}{2} p \frac{L_{m}}{L_{r}} \psi_{r} i_{s q}
$$

The bloc diagram of sensorless indirect field oriented control induction motor drive is indicated on Fig.1. 


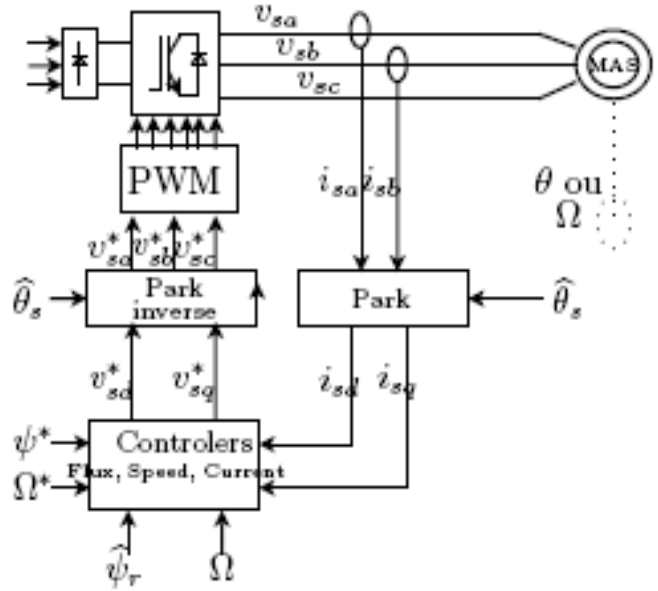

Fig.1. Block diagram of RFOC IM simulator

\section{MODEL REFERENCE ADAPTIVE SYSTEM}

There are three approaches developed in literature of MRAS based speed estimators [7]:

- The rotor flux error based MRAS scheme

- The back EMF error based MRAS scheme

- Stator current error based MRAS scheme

The model reference approach (MRAS) makes use of two machine models of different structures that estimate the same state variable on the basis of different sets of inputs variables [3]. MRAS estimators consist of a reference model (which does not include the speed estimate) and an adjustable model (which include the speed estimate).

\section{MRAS BASED ON ROTOR FLUX ESTIMATION}

In this approach, reference model is the voltage model it's the induction motor model. Its equation is derived from (1) and (2). In the stationary reference frame $\left(\omega_{s}=0\right)$, so:

$$
\underline{\psi}_{r v}=\int\left(\underline{u}_{s} R_{s} i_{-s}-\sigma L_{s} \frac{d}{d t} \underline{i}_{s}\right) d t
$$

The adjustable model is the current model its equation is obtained from (1b) and (2)

$$
\frac{d}{d t} \underline{\psi}_{r i}+\frac{1}{T_{r}} \underline{\psi}_{r i}=j \hat{\omega} \underline{\psi}_{r i}+\frac{L_{m}}{T_{r}} \underline{i}_{s}
$$

Model (5), generates the rotor flux estimate from the measured stator current and from the estimated speed $(\hat{\omega})$ which is obtained through a PI controller from an error signal $\varepsilon$. This error represents difference between the two estimated flux vectors.
Where $\psi_{-r v}$ the rotor flux estimated by the reference model (voltage model), and $\underline{\psi}_{r i}$ is the rotor flux estimated by the adjustable model (current model).

Fig.2 illustrates the basic structure of rotor flux based MRAS approach.

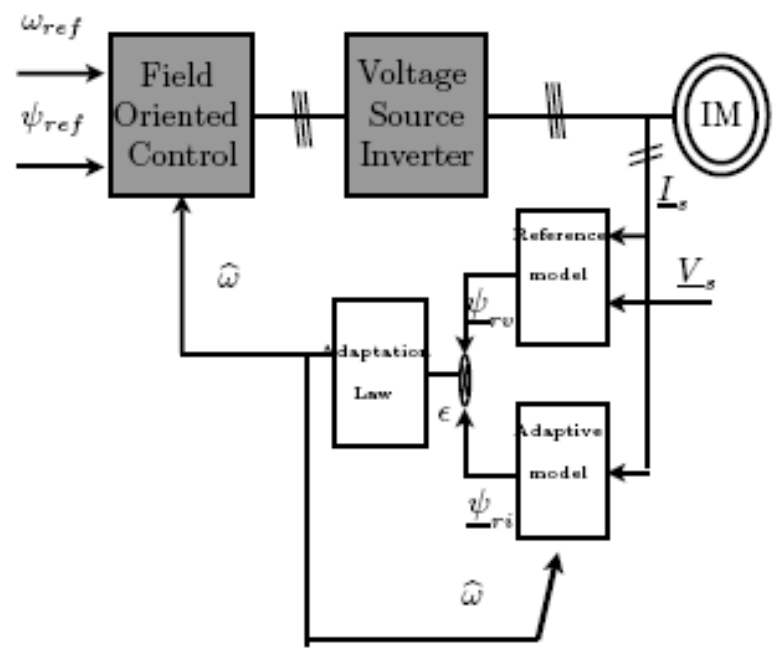

Fig.2. Block diagram of rotor flux MRAS method

\section{A. ADAPTATION LAW}

From model (4), rotor flux is

$$
\frac{d}{d t} \underline{\psi}_{r}=\left(-\frac{1}{T_{r}}+j \omega\right) \underline{\psi}_{r}+\frac{L_{m}}{T_{r}} \underline{i}_{s}
$$

From model (5), estimated rotor flux is

$$
\frac{d}{d t} \underline{\hat{\psi}}_{r}=\left(-\frac{1}{T_{r}}+j \hat{\omega}\right) \underline{\hat{\psi}}_{r}+\frac{L_{m}}{T_{r}} \underline{i}_{s}
$$

System describing estimation error is

$$
\frac{d}{d t} \underline{e}_{\psi}=\left(-\frac{1}{T_{r}}+j \omega\right) \underline{e}_{\psi}+j(\omega-\hat{\omega}) \underline{\hat{\psi}}_{r}
$$

It's important to ensure system (8) stability. It's guaranteed if error $\varepsilon$ tend to zero. The adaptation law is obtained from Lyapunov theory [1].

The estimated speed expression can be written as:

$$
\hat{\omega}=\left(K_{p}+\frac{K_{i}}{s}\right) \varepsilon
$$

With: 
$\varepsilon=\mathfrak{I}\left(\psi_{r} \hat{\psi}^{\prime}{ }_{r}\right)=\psi_{r \beta} \hat{\psi}_{r \alpha}-\psi_{r \alpha} \hat{\psi}_{r \beta}$

Figures (3), (4) are obtained with nominal torque $T_{L o}=7(N . m)$ applied at $\mathrm{t}=2 \mathrm{~s}$. Fig. 3 indicates the system behavior during steady state condition at high speed (150 $\mathrm{rad} / \mathrm{s}$ ) and during transient with speed inversion. Fig.4 shows the system performance in the low speed region $(10 \mathrm{rad} / \mathrm{s})$.
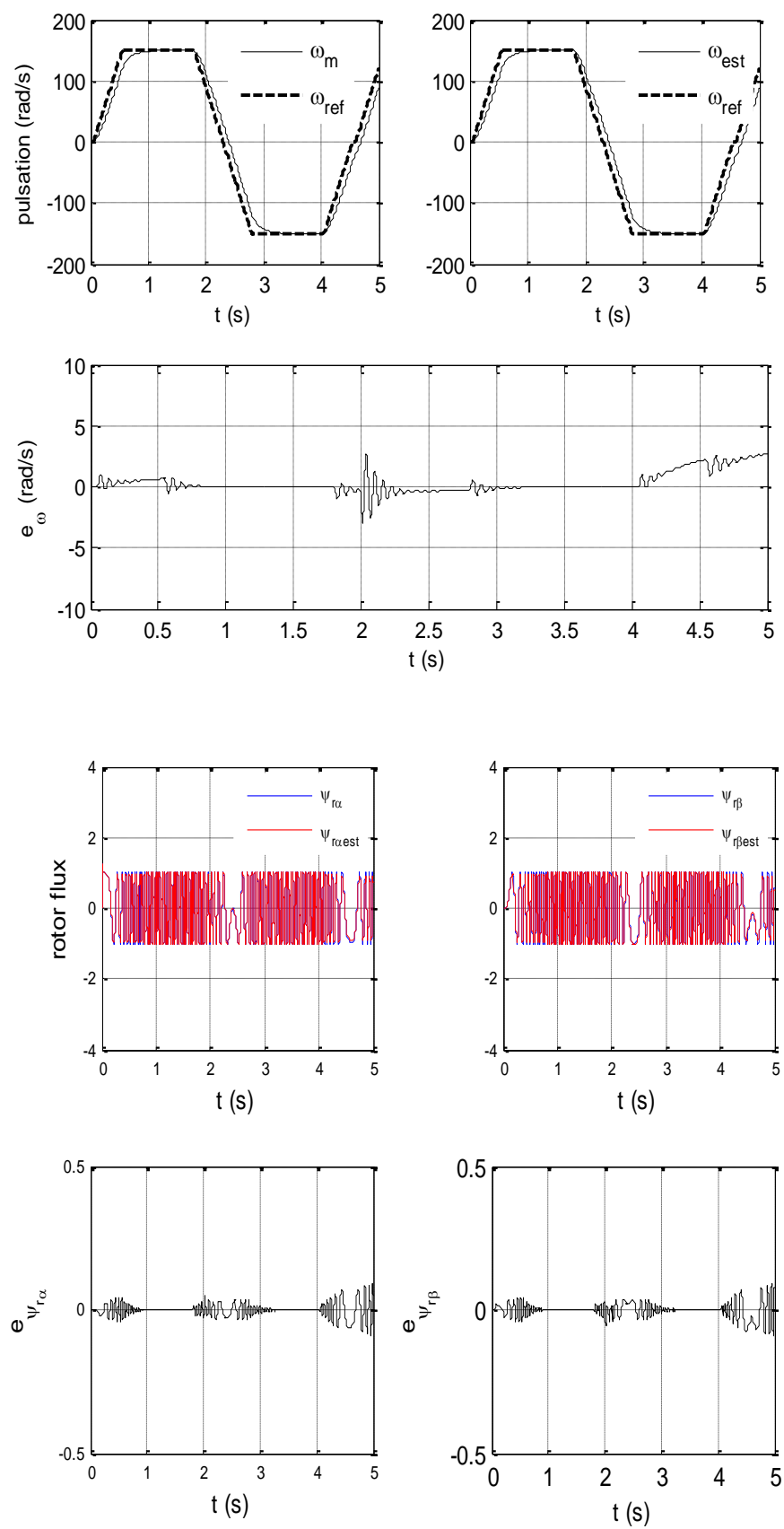

Fig. 3. Four quadrant operation at high speed for $K_{p}=10, K_{i}=10000$
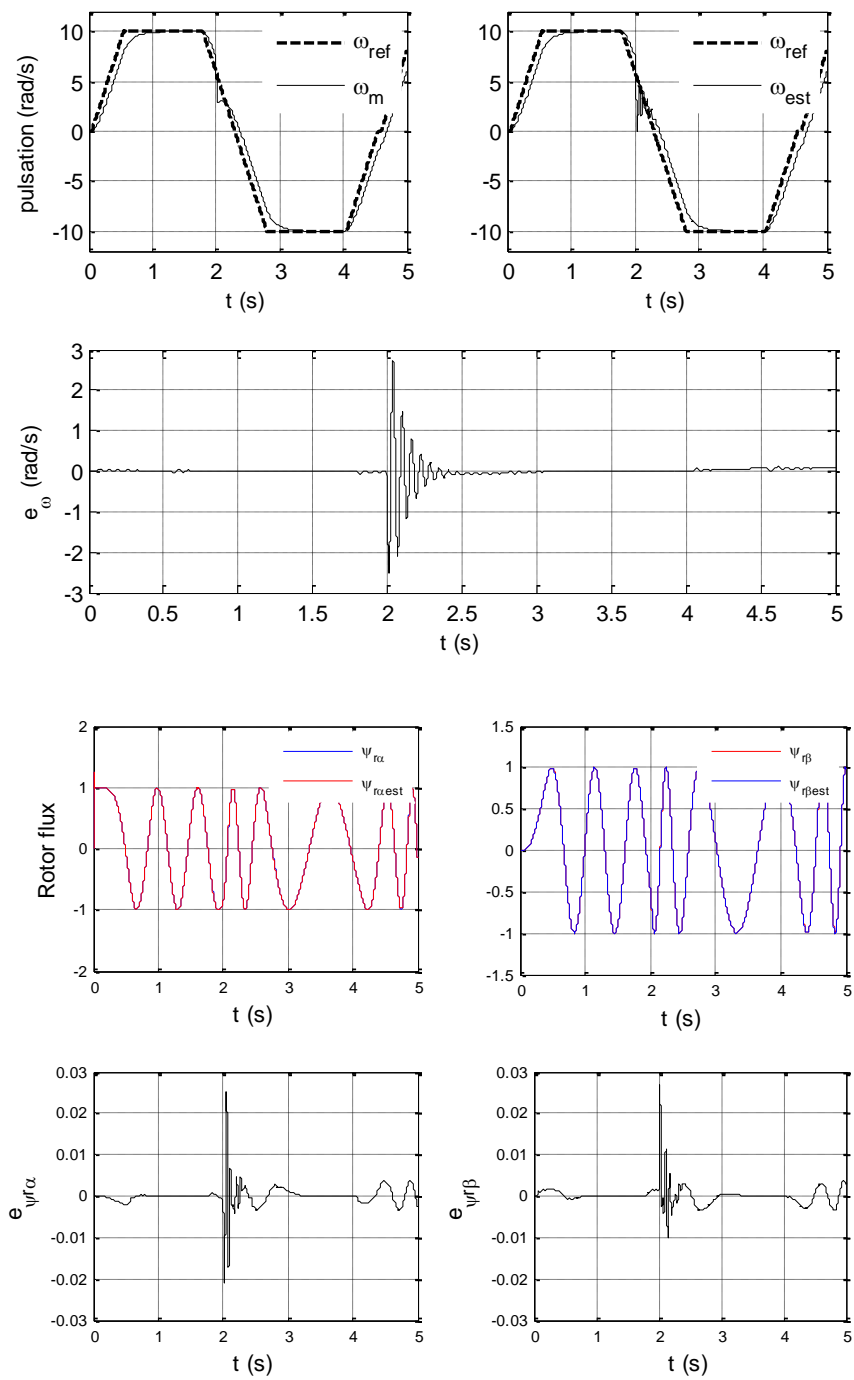

Fig.4. Four quadrant operation at low speed for $K_{p}=10, K_{i}=10000$

Simulation results indicate that the fluxes of the adjustable model converge to the reference fluxes, the speed prediction has small or no steady-state error and the dynamics of the speed estimate is acceptable. Generally, the classical MRAS works very well if ideal integration can be used in both models. Nevertheless, in a real system, pure integration cannot be implemented.

\section{MRAS BASED ON BACK EMF ESTIMATION}

The primary method suffers from problems associated with pure integration. To avoid the problems, an MRAS based on back EMF is proposed. The rotor speed is generated from an error signal calculated by the dot product of the stator current vector and the back EMF difference vector $[7,8]$.

The reference model is derived from (4):

$$
\frac{d}{d t} \underline{\psi}_{r v}=\frac{L_{r}}{L_{m}}\left(\underline{u}_{s}-R_{s} i_{-s}-\sigma L_{s} \frac{d}{d t} \underline{i}_{s}\right)=\underline{E}_{v}
$$


The adjustable model is derived from Eq. (5)

$$
\frac{d}{d t} \hat{\hat{\psi}}_{r i}=\left(-\frac{1}{T_{r}}+j \hat{\omega}\right) \hat{\hat{\psi}}_{r i}+\frac{L_{m}}{T_{r}} \underline{i}_{s}=\underline{\hat{E}}_{i}
$$

The adaptive law of the estimator is given by [7]:

$$
\hat{\omega}=\left(K_{p}+\frac{K_{i}}{s}\right) \varepsilon
$$

With:

$$
\varepsilon=\left(j \underline{i}_{S}\right)^{T} \Delta \underline{E}_{v i}
$$

$\Delta_{\underline{E}_{v i}}=\underline{E}_{v}-\underline{\hat{E}}_{i}:$ It's the back EMF difference vector.

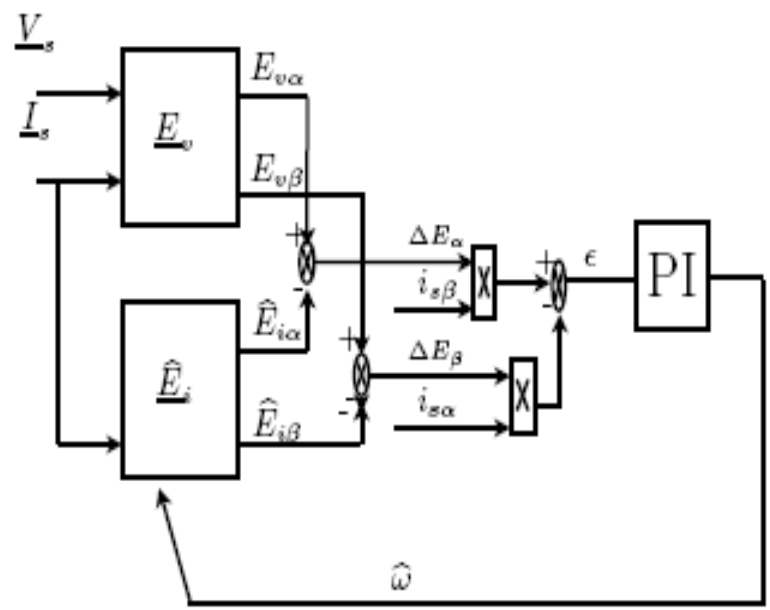

Fig. 5. Block diagram of back EMF based approache

Fig.5 indicates the block diagram of the proposed MRAS based on back EMF calculation. For this case simulations are done for different operating points in monitoring and regenerating modes Fig.6.

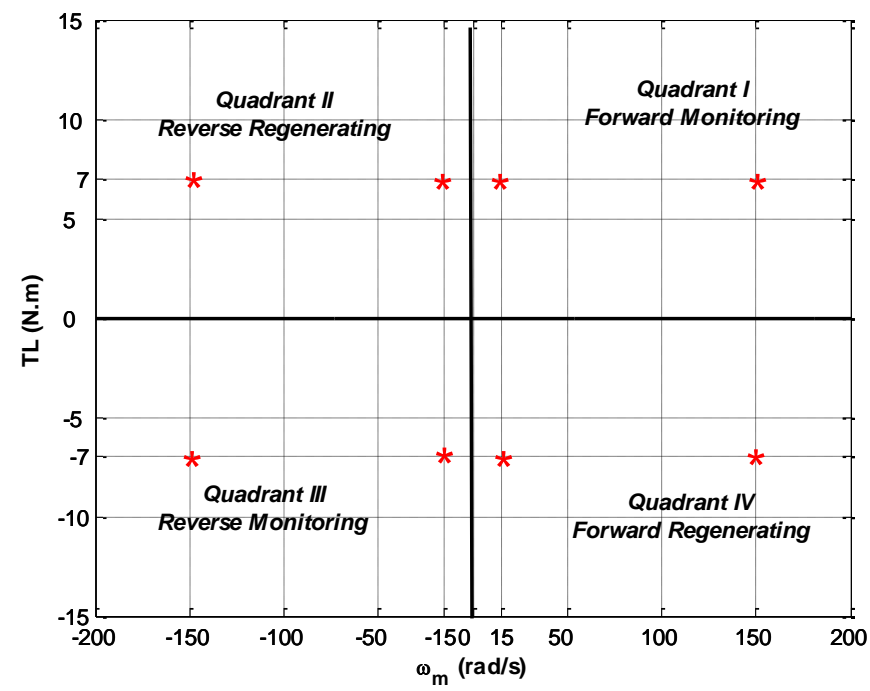

Fig.6. Operating points in the torque speed plane
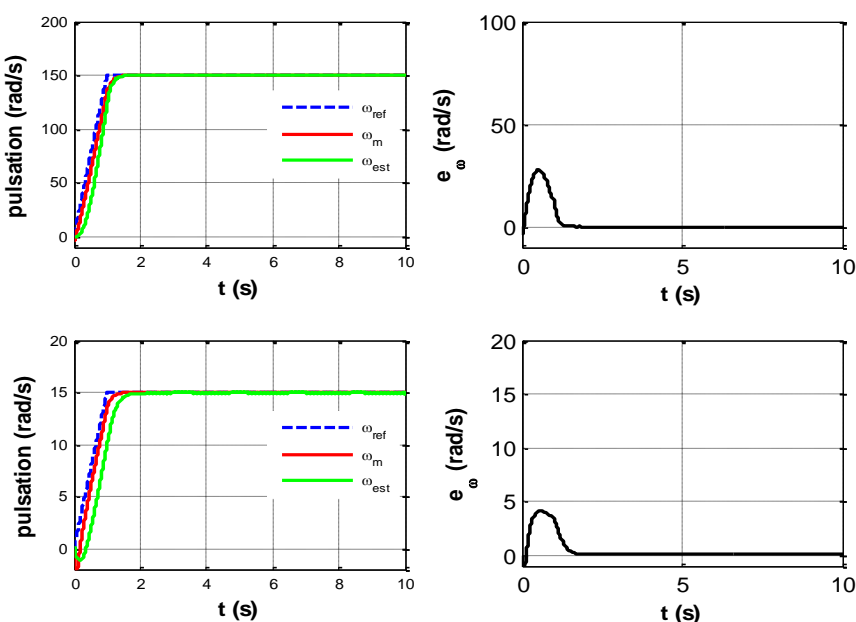

Fig. 7. Quadrant I Forward monitoring mode: reference speeds $\omega_{\text {ref }}=150(\mathrm{rad} / \mathrm{s}), \omega_{\text {ref }}=15(\mathrm{rad} / \mathrm{s})$ and load torque $T_{L o}=7(\mathrm{~N} . \mathrm{m})$
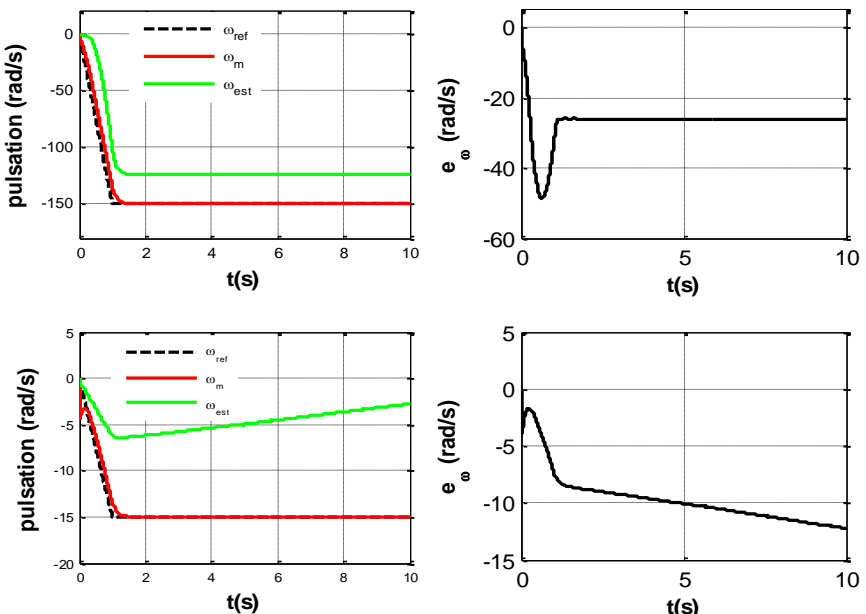

Fig.8. Quadrant II Reverse regenerating mode: reference speeds $\omega_{\text {ref }}=-150(\mathrm{rad} / \mathrm{s}), \omega_{\text {ref }}=-15(\mathrm{rad} / \mathrm{s})$ and load torque $T_{L o}=7(\mathrm{~N} . \mathrm{m})$
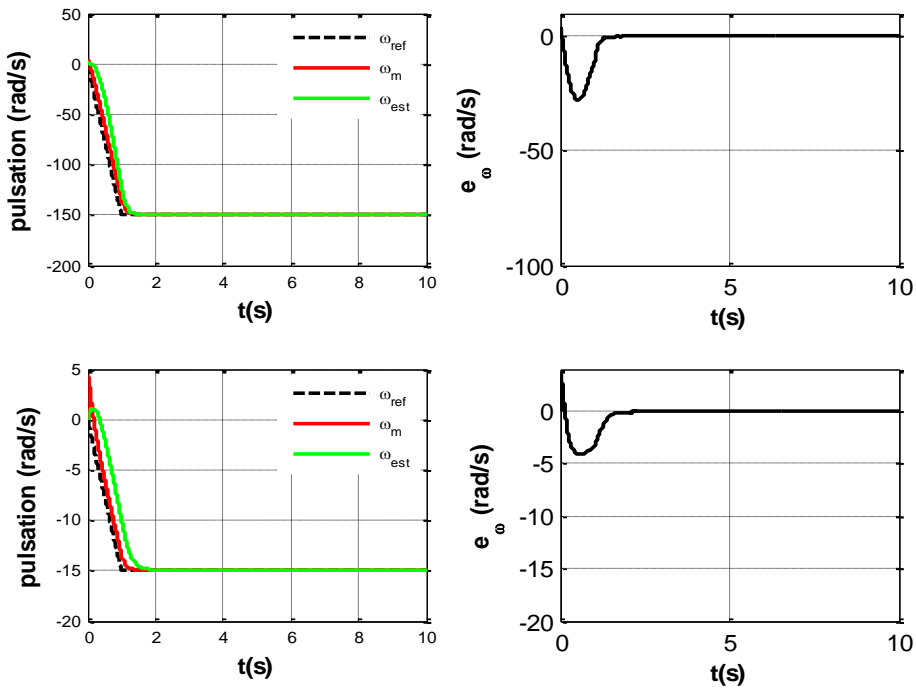

Fig.9. Quadrant III Reverse monitoring mode: reference speeds $\omega_{\text {ref }}=-150(\mathrm{rad} / \mathrm{s}), \omega_{\text {ref }}=-15(\mathrm{rad} / \mathrm{s})$ and load torque $T_{\text {Lo }}=-7(\mathrm{~N} . \mathrm{m})$ 

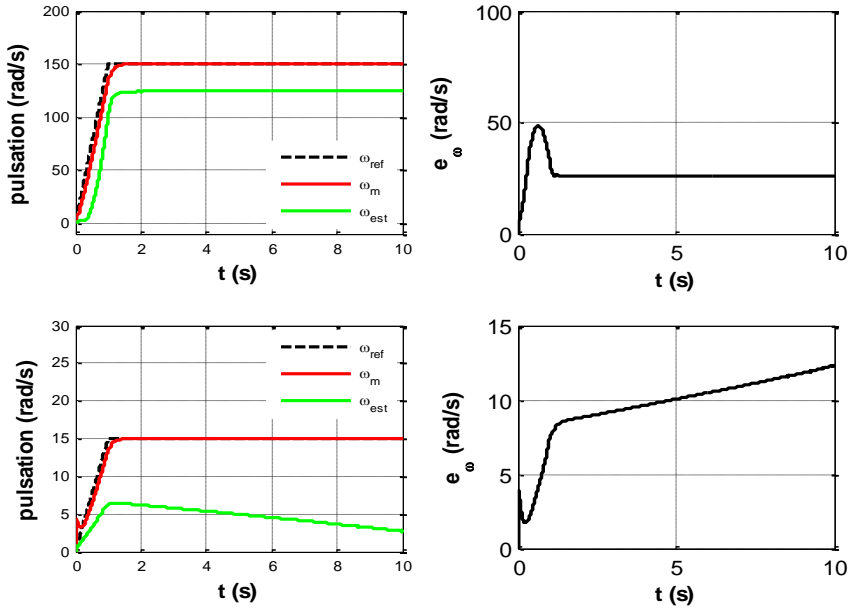

Fig.10. Quadrant IV Forward regenerating mode: reference speeds $\omega_{\text {ref }}=150(\mathrm{rad} / \mathrm{s}), \omega_{\text {ref }}=15(\mathrm{rad} / \mathrm{s})$ and load torque $T_{L o}=-7(N . \mathrm{m})$

Fig.7 and Fig.9 shows the system behavior for high and low speed drive. It can be seen that in monitoring mode (Quadrant I and Quadrant III), estimated speed converge to real rotor speed, speed error tend to zero. Fig.8 and Fig10 show that divergence is highlighted between real speed and estimated speed. Stability of this system is not guaranteed in regenerating mode (Quadrant II and Quadrant IV).
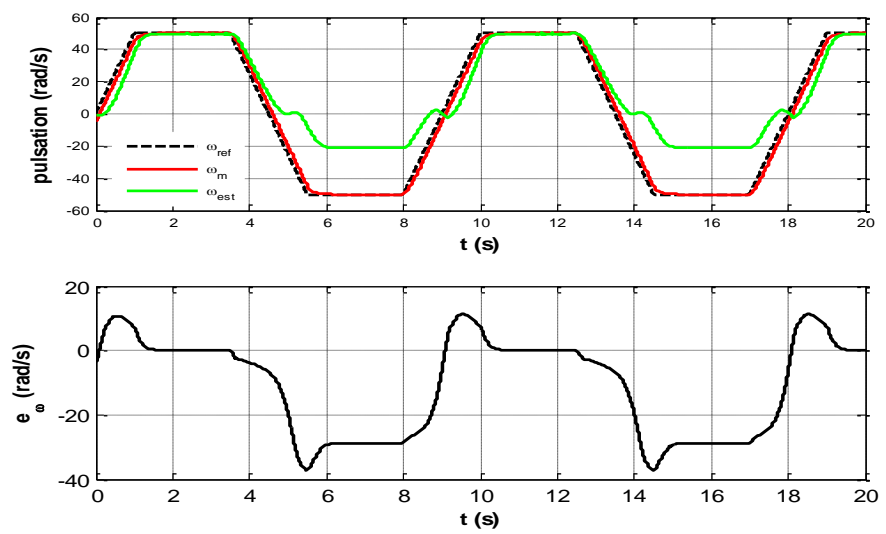

Fig.11. Reversing speed operation: $\omega_{\text {ref }}=50(\mathrm{rad} / \mathrm{s})$ to $\omega_{\mathrm{ref}}=-50(\mathrm{rad} / \mathrm{s})$
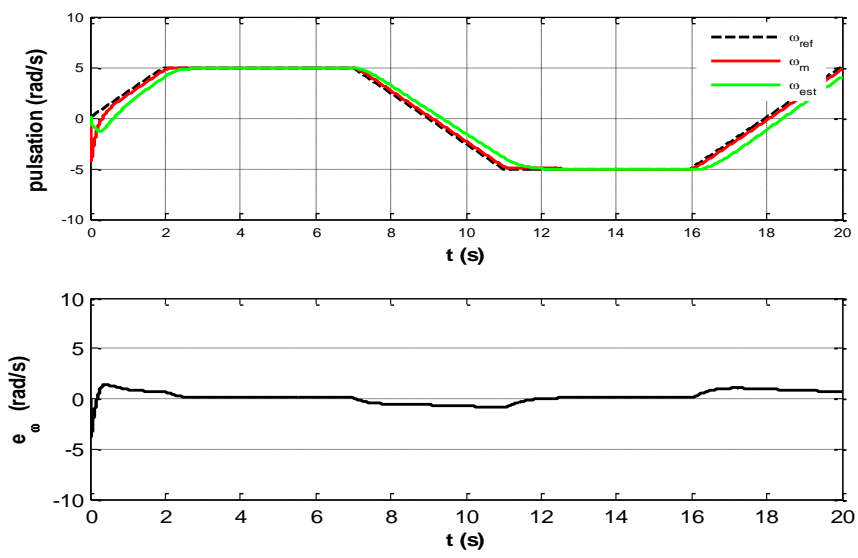

Fig.12. Reversing speed operation: $\omega_{\text {ref }}=5(\mathrm{rad} / \mathrm{s})$ to $\omega_{\text {ref }}=-5(\mathrm{rad} / \mathrm{s})$
Dynamic performances were tested during transient with speed inversion from $\omega=50(\mathrm{rad} / \mathrm{s})$ to $\omega=-50(\mathrm{rad} / \mathrm{s})$ (Fig.11) and from $\omega=5(\mathrm{rad} / \mathrm{s})$ to $\omega=-5(\mathrm{rad} / \mathrm{s})$ (Fig.12) under nominal torque $T_{L o}=7(\mathrm{~N} . \mathrm{m})$. Results obtained confirm that system is stable in monitoring mode and unstable for zero speed and unstable in regenerating mode but not for all operating points in torque speed plane.

For $\omega_{\text {ref }}=-50(\mathrm{rad} / \mathrm{s})$ and load torque $T_{L o}=7(N . \mathrm{m})$ system is unstable (figure 11). For $\omega_{\text {ref }}=-5(\mathrm{rad} / \mathrm{s})$ and load torque $T_{L o}=7(N . m)$ system is stable (Fig.12).

\section{CONCLUSIONS}

MRAS based on rotor flux estimation had well tracking performances at high speed and even at low speed operation. Estimated and measured speeds, are equal each other not only for the steady-state operation but also under speed reference and load torque changes but pure integration process causes drift problems. MRAS based on back EMF estimation approach can be easily practiced but it suffers from instabilities in re-generating mode. The sensorless control based on back EMF degrades fast at low speed, at zero speed. To ensure good behavior, first stability analysis must be done to know unstable zones then adaptation law will be modified to have good tracking performances.

\section{ACKNOWLEDGMENT}

The study is selected from $1^{\text {st }}$ International Conference on Electrical Energy and Systems October 22-24 $4^{\text {th }}$.

\section{REFERENCES}

[1] H. Kubota and K. Matsuse, " DSP-Based Speed Adaptive Flux Observer of Induction Motor", IEEE Transactions on Industry Applications, vol. 29, no.2, 1993.

[2] C. Schauder, "Adaptive speed identification for vector control of Induction Motor without rotational transducers", in Conf. Rec. IEEE IAS Annu. Mtg., p. 493-499, 1988

[3] J. Holtz, "Methods for Speed Sensorless Control of AC Drives", Published i K. Rajashekara (editor) Sensorless Control of AC Motors. IEEE press book. 1996.

[4] M. Rashed and F. Stronach, "A stable MRAS-based sensorless vector control induction motor drive at low speeds", in Conf. Rec. IEEE IEMDC, 2003.

[5] M. Suman and C. Chakraborty, "Model Reference Adaptive ControllerBased Rotor Resistance and Speed Estimation Techniques for Vector Controlled Induction Motor Drive Utilizing Reactive Power", IEEE Transactions on industrial electronics, vol.55, no.2, 2008.

[6] C. Chaigne, E. Etien, S. Cauet, L. Rambault, "Commande vectorielle sans capteur des machines asynchrones", Hermes science, Lavoisier, 2005.

[7] N. Marwali and A. Keyhani, " Comparative Study of Rotor Flux Based MRAS and Back EMF Based MRAS Speed Estimators for Speed 
Sensorless Vector Control of Induction Machines", IEEE Industry Applications Society Annual Meeting, New Orleans, Louisiana, 1997.

[8] M. Rashed and F. Stronach and P. Vas, "A stable back EMF MRASbased sensorless low speed induction motor drive insensitive to stator resistance variation”, IEE Proc-Electr, Power Appl, vol.151, no.6, 2004.
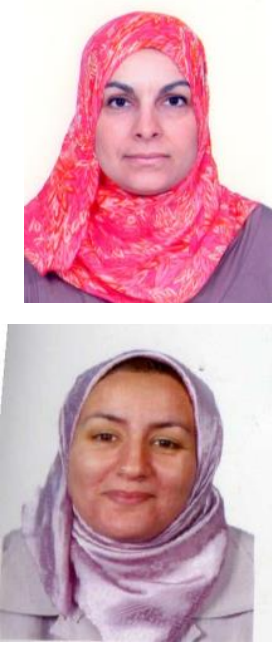

\section{BIOGRAPHIES}

NADIA BEN SI ALI was born in Annaba in Algeria. She received the engineering and DEA. Degrees from Badji Mokhtar Annaba University, Algeria in 1994 and 1997 respectively. She obtained the Ph.D. degree in 2008 from Badji Mokhtar Annaba University, Algeria. She is with the electrical Engineering Department of the same university. Her fields of research are electrical power converters and sensorless control of motors drive.

NADIA BENALIA was born in Annaba in Algeria. She received the engineering and DEA. Degrees from Badji Mokhtar Annaba University, Algeria in 1993 and 1996 respectively. She obtained the Ph.D. degree in 2010 from Badji Mokhtar Annaba University, Algeria. She is with the electrical Engineering Department of the same university. Her fields of research are optimization using genetic algorithms and stability of electrical networks. 